\title{
VIVIR AFUERA: UNA ERÓTICA LETAL ${ }^{1}$
}

\author{
POR \\ Alexis CANDia CÁceres \\ Universidad de Playa Ancha, Chile
}

Vivirafuera (1998) es una de las novelas más logradas de la narrativa hispanoamericana de los últimos años. La novela de Fogwill evidencia una notable y variada técnica narrativa, un ensamblado preciso de una serie de historias que terminan anudándose en Buenos Aires y un sombrío retrato de la Argentina de Carlos Menem que, según parte importante de la crítica, la han situado como la gran novela argentina de la década de $1990 .{ }^{2}$ La novela es, además, uno de los textos que, en mayor medida, encarna la poética trazada por el escritor argentino: "[...] 'sólo se puede escribir literatura en contra de algo" (Munaro). Fogwill no sólo escribe en contra de la simbólica menemista, lo que constituye, por lo demás, la lectura más evidente del texto, sino contra la representación aséptica y restrictiva del erotismo en la narrativa hispanoamericana previa a la década de 1960. Bajo esta perspectiva, es posible sostener que Fogwill recoge el guante arrojado por Julio Cortázar varios años antes cuando establece que:

En América Latina, libro dos grandes batallas, una por la liberación humorística, otra por la liberación erótica, por un humorismo y erotismo integrales que nos liberen de todos los tabúes que nos llegan, sobre todo, de la tradición hispánica [...] Contra los comisarios que no tienen sentido del humor y además son malos amantes. (Yurkievich en Gundermann)

Cortázar fustiga la construcción de discursos eróticos marcados por la presencia de tabúes que afectan la calidad del modo de representación del eros. De ahí que abogue por un erotismo que logre un feliz desenlace en la ecuación " $[\ldots .$.$] 'erotismo =$ sexo + inteligencia, ojos + inteligencia, lengua + inteligencia, dedos + inteligencia”"

1 Proyecto Postdoctorado 2012 núm. 3120104: "Las mil formas de Venus en la narrativa hispanoamericana contemporánea", financiado por el Fondo Nacional de Ciencia y Tecnología, Fondecyt. Investigador Responsable: Iván Alexis Candia Cáceres.

2 La novela le valió a Fogwill el Premio Elsa Kalish a la mejor novela de los 90’ y el Premio Nacional de Literatura 2004 de Argentina. 
(Cortázar en Gallardo). El llamado de Cortázar tuvo una recepción importante en la narrativa argentina de las décadas de los sesentas y setentas. Martina López establece que la literatura trasandina de esas décadas tiene como elemento común la voluntad de irritar y provocar a partir de la narración de los cuerpos, lo que supone "[...] volverlos protagonistas del relato y construir el conflicto en la confrontación que establecen. En este sentido, lo sexual es un aspecto fundamental, aunque no el único. En cambio, las relaciones de poder pueden ponerse en juego a través de distintas localizaciones de lo corporal" (López 183). Nanina de Germán Leopoldo García, El fiord de Osvaldo Lamborghini, El frasquito de Luis Guzmán y La boca de la ballena de Héctor Lastra se pueden situar como parte de una producción narrativa orientada a escribir los cuerpos y el erotismo argentino. Para López estas novelas dan cuenta de un erotismo que implica un cruce con el poder: "El cuerpo propio y el ajeno están allí marcando límites o invitando a borrarlos, posibilitando encuentros o fusiones, imponiendo necesidades, abriendo o clausurando los deseos; están allí [...] disputándose el poder" (López 183). A partir de la década de 1980, la narrativa argentina comienza a incorporar nuevas miradas sobre el fenómeno erótico. Así, se abre hacia la perspectiva femenina con textos tales como $\mathrm{La}$ rompiente de Reina Roffé y Canon de alcoba de Tununa Mercado, las que incorporan “[...] la dimensión del placer donde el autoconocimiento femenino está en juego y es en todo caso en él en donde late una perspectiva política" (López 183). A ello habría que agregar la inclusión de nuevas voces que narran el universo homosexual.

En este escenario es necesario situar a Vivir afuera. Fogwill no sólo prosigue la batalla desplegada por Cortázar y por la serie de escritores que asumieron su llamado, sino que llega mucho más lejos en la liberación erótica, la transgresión de los tabúes y en la combinación cuerpo e inteligencia de lo planteado por el autor de Rayuela, contando historias de cuerpos que se sitúan al margen del poder y que, en última instancia, terminan transgrediéndolo.

Daniel Link sostiene, en esta línea, que "[...] en los libros de Fogwill la experiencia sexual es una investigación pura. Allí, en ese frenesí de la carne, en esa pérdida de toda moral y todo límite, la sabiduría y la inteligencia de Fogwill encuentran el punto de vista para hablar de todo y para todos" (Link). Para Link, la exploración erótica de Fogwill conduce a una investigación que busca cruzar los límites de la representatividad y desafiar la forma de entender la sexualidad:

[...] Fogwill ha hecho del sexo una experiencia contable (narrable, pero también computable). El sexo importa en sus ficciones porque es una experiencia pura que desafía o interroga toda trascendencia, porque sirve como motor de "la juventud" [...] porque desencadena historias y porque desviste la imaginación del narrador. (Link)

En Vivir afuera Fogwill sigue las huellas de siete personajes en Buenos Aires, tal como reconoce el propio autor de la novela: "La estructura surge del azar de los

Revista Iberoamericana, Vol. LXXXI, Núm. 250, Enero-Marzo 2015, 233-251 ISSN 0034-9631 (Impreso)

ISSN 2154-4794 (Electrónico) 
encuentros y desencuentros de la noche porteña y está más que nada condicionada por lo que a medida que escribía advertía que había pasado por alto entre todo lo que por entonces quería manifestar" (Munaro). A lo largo de las once horas que dura el relato, que comienza en medio de la noche porteña y finaliza en la mañana, Fogwill plasma las más variadas formas de la escenificación erótica protagonizadas por Pichi, Susi, Wolff, Mariana, Saúl, Diana y Cecilia, los que, a su vez, dan cuenta de las aventuras de variados personajes, como el "judío errante", el cura y la evangélica, entre otros, dando forma a un erotismo transgresor, situado en la periferia, que supera los límites trazados por la narrativa hispanoamericana.

Vivir afuera puede ser leída, entonces, a partir de la presencia de una "erótica letal" que radicaliza el significado y la representación del erotismo en la narrativa hispanoamericana, rompiendo brutalmente con los tabúes e incorporando una serie de variables eróticas que habían sido excluidas de las letras continentales. Fogwill da luz verde a la construcción de una lubricidad extrema que alcanza su punto máximo al jugar con la muerte, cruzando la amenaza y el terror de la aniquilación con el placer propio de una actividad sexual que corre al borde del abismo. El cruce de erotismo y enfermedad planteado por Fogwill constituye todo un desafío a la forma de entender el vínculo del sexo y el SIDA ya no sólo en Hispanoamérica, en particular, sino en Occidente, en general.

\section{Malos AiReS}

Vivir afuera tiene una nota final que puede dar luces del sentido del mundo y de los hombres/mujeres que cruzan la novela. En una página de un libro de Martín Buber, Saúl encuentra la siguiente anotación:

Los hombres y el mundo. Tres hombres, dos mundos. Mundo del bien, mundo del mal. Hombres locos, boludos, y hombres hijos de puta. En el mundo del mal los locos se vuelven más locos, los boludos más boludos y los hijos de puta más hijos de puta. En el mundo del bien no se puede pensar, porque ya se fue lejos de nuestro alcance. (Fogwill, Vivir afuera 289)

Fogwill traza un sombrío y retorcido relato de la Argentina menemista. La prostitución, la trata de blancas, el tráfico de drogas, el abuso del poder son algunos de los temas desarrollados en Vivir afuera, lo que conduce a plasmar un oscuro retrato del auge neoliberal de la década de 1990, el que constituye, en definitiva, el anverso del supuesto éxito económico, político y social de la experiencia capitalista trasandina. Fogwill compone un relato del mal centrado en representar la perversión del cuerpo social que ha acabado por contaminar a la capital federal. De ahí que el propio Fogwill

Revista Iberoamericana, Vol. LXXXI, Núm. 250, Enero-Marzo 2015, 233-251 ISSN 0034-9631 (Impreso)

ISSN 2154-4794 (Electrónico) 
sostenga respecto de los personajes de Vivir afuera que: "[...] todos los personajes son virtualmente 'lumpenes', gente desclasada y traidora a su clase” (Munaro).

Así, nos encontramos con una galería "lumpen" en la que es posible encontrar, por ejemplo, al Pichi, traficante y productor de drogas -tiene una plantación de mariguanaque realiza una serie de "transas" con estupefacientes. Fogwill retoma al Pichi de Los pichiciegos (1983), su primera novela, texto en el que construye un crítico relato sobre la guerra de las Malvinas. Allí, el Pichi forma parte de una comunidad de desertores del ejército argentino, "los pichiciegos", que viven en una construcción subterránea y que hacen lo que sea necesario por sobrevivir en medio del conflicto. Fogwill toma el nombre de una especie de insectos que dan luces de lo que son "los pichiciegos": "El pichi es un bicho que vive debajo de la tierra. Hace cuevas. Tiene cáscara dura, una caparazón, y no ve. Anda de noche. Vos lo agarrás, lo das vuelta, y nunca sabe enderezarse, se queda pataleando panza arriba" (Fogwill, Los pichiciegos 40). En medio de la Argentina menemista, el Pichi sigue actuando como lo hacía en las Malvinas: sin concesiones, sin límites, sin miramientos, concentrándose, en todo momento, en seguir con vida. Precisamente, ese código de conducta mantendrá Pichi cuando, quince años después y como único sobreviviente de "los pichiciegos", realice una serie de negocios con la policía:

- La coca, el ácido, las pepas y las anfetas son una mierda, son drogas inglesas...

Que algo fuera inglés era lo peor que sabía decir el Pichi. Últimamente, que estaba metiéndose en mejicaneadas por la zona norte, cuando aparecía con plata o con droga para cambiar explicaba:

- Anoche reventamos a unos ingleses... -aunque jamás hubiera ingleses para apretar, y aunque la mayoría de los revendedores que apretaban fuesen villeros de San Isidro o de la zona de El Tigre. (Fogwill, Vivir afuera 36)

Las transacciones del Pichi son respaldas por Susi-su pareja-y por Mariana, la que, además de ayudarle en el tráfico de drogas es una prostituta que, según Susi: “[...] hace gatos a veces de doscientos y de trescientos pesos" (Fogwill, Vivir afuera 36). Además, Mariana colabora de manera soterrada con la policía en la vigilancia y el control de los distintos criminales locales, constituyendo parte del complejo panóptico de la novela.

En la parte más alta de la pirámide delictual de Vivir afuera se encuentra Piero, quien no sólo es responsable de abuso y violación de menores sino que juega un rol central en una amplia red de trata de blancas que lleva a muchachas argentinas a España:

Tiene tocos de guita... Esconde... Saca guita de minas... Se las reparte con los Fornaroli de Quilmes... Ponen pibitas a yirar... Después arreglan con la yuta de que les hagan la vida imposible... A las pibitas se les corta el chorro de plata y ahí les dicen que es por la yuta y que tienen que dejar de yirar. Las pibitas no pueden parar. Ellos saben que las pibitas no pueden parar, que necesitan pilchas, falopa, pagar la pensión, médicos... Y

Revista Iberoamericana, Vol. LXXXI, Núm. 250, Enero-Marzo 2015, 233-251 ISSN 0034-9631 (Impreso)

ISSN 2154-4794 (Electrónico) 
entonces caen y les dicen que les consiguen un laburo en un sauna de Madrid... Y las mandan allá a España... Y allá les empiezan con la misma historia. Las forras son forras y vuelven a comérsela: clausuran el sauna, las fichan, las amenazan con deportarlas y ficharlas en Interpol y ellos las sacan de ahí y las mandan a los pueblitos, o a Argelia... (Fogwill, Vivir afuera 188)

Ahora bien, no sólo es posible leer Vivir afuera desde una escisión bien/mal sino que ésta debe ser complementada a partir de la perspectiva adentro/afuera. De ahí que el propio Fogwill sostuviera que el título de la novela aludía " [... a todo lo que alguien pueda sentir al escucharla. Fuera de la ciudad, fuera de la ley, fuera de las obligaciones cotidianas, fuera de sí" (Munaro). No hay mayor constante en el texto que esta división. Fogwill crea una novela del borde, donde todos los personajes que intervienen en el texto son marginales, ya sea por razones genéricas, económicas, sociales, culturales, entre otras:

La mujer, el judío, el negro, el pobre, el drogadicto, el enfermo de sida, el viejo, el que todavía vive de las ideas de otra década, el extranjero ilegal, el homosexual, el que opera fuera de la ley, el ex convicto, el ex combatiente... Todos ellos son marginales $\mathrm{y}$, a su vez, todos marginan, todos tienen de algún tercero una idea discriminatoria: ninguno está, entonces, en el centro de nada. (Cristal)

Vivir afuera exhibe una amplia variedad de exclusiones que abarcan desde la manifiesta marginalidad del mundo delictual en que viven Piero, Mariana o Susi hasta exclusiones más sutiles y complejas. Bajo este prisma, se sitúa la segregación generacional de Wolff, quien, ad portas de cumplir los sesenta años, se mueve en un mundo que, hace mucho tiempo, dejó atrás los códigos de los setentas. Asimismo, es posible situar a Saúl, destacado investigador del VIH que, sin embargo, experimenta una situación económica que lo hace sentirse al margen de su comunidad étnica, punto que, por lo demás, deja en claro su novia: “¡Y ahí te volvió a salir el judío resentido de Villa Crespo...!" (Fogwill, Vivir afuera 68). Algo similar pasa con Pichi en cuanto a su condición de ex combatiente de las Malvinas que es incapaz de olvidar el conflicto. Asimismo, me interesa destacar a uno de los pacientes de la clínica en la que trabajan Saúl y Cecilia, un gordo que experimenta una doble marginación por su condición de homosexual y enfermo de SIDA. De hecho, en un texto que le deja a Cecilia se asume como el "judío errante", figura legendaria que habría sido condenada a errar por la tierra debido a que se negó a darle agua a Jesús en su camino a la cruz. La errancia sólo terminaría con la segunda venida de Cristo:

"Yo soy el judio errante. Soy el que siempre se equivoca. He cometido el peor de los pecados: yo fui feliz justo alli donde a los de mi raza les exigieron padecer [...] Yo, en el velorio de papá, cuando no aguanté más la cara de pescado de mi vieja y sus

Revista Iberoamericana, Vol. LXXXI, Núm. 250, Enero-Marzo 2015, 233-251 ISSN 0034-9631 (Impreso)

ISSN 2154-4794 (Electrónico) 
hermanas y cuñadas, bajé a la pizzería y encontré al chongo de mi vida. La tierra prometida de mi noche más triste era aquel mozo tucumano que en cuanto me sirvió la primera copa [...] se dio cuenta de que íbamos ser él uno para la otra. (Fogwill, Vivir afuera 202; itálicas en el original)

Martín Cristal asume que Vivir afuera realiza un crudo retrato del funcionamiento del poder en la Argentina menemista, erigiéndose como una fuerza centrífuga, excluyente, "[...] que giraba a la velocidad de los mass media, generando un espacio central que dejaba a todos los que no comulgaban con él en la periferia de aquella zona: al margen. Era un poder en forma de salvavidas: un hueco en el centro [...] rodeado de un amplio 'sálvese quien pueda', perimetral y circular" (Cristal). El poder no asume una posición indiferente frente a la periferia, todo lo contrario, adopta una actitud vigilante que apunta a controlar la actuación de los hombres y mujeres que deambulan por el margen, erigiendo, en definitiva, un panoptismo que tiende a detectar a sus potenciales amenazas.

La escisión de Vivir afuera evidencia la compleja circulación de cuerpos que se produce en las ciudades latinoamericanas, donde se ha intentado establecer cierta jerarquización del espacio urbano. Fogwill hace que sus personajes se desplacen por los bordes de la urbe ya sea en el plano espacial o en el simbólico. Mientras Pichi, Susy y Mariana se mueven por los arrabales, los sitios eriazos o los espacios subterráneos (bares, moteles, carreteras abandonadas); Wolff, Saúl y Cecilia resemantizan distintos lugares dotándolos de una marginalidad novedosa. Frente a esto, es interesante la visión de Lucía Guerra sobre la construcción de la cartografía urbana en orden a que ésta omite todo relieve y toda carga connotativa. Guerra piensa que la simplicidad de las líneas que representan las calles, plazas y parques de la ciudad esconde una compleja trama de eventos y diversas circulaciones, una constelación de ejes cambiantes y, más que nada, un volumen que burla todos los intentos de reducir esa ciudad al trazo escueto y simétrico:

En aquellas líneas que responden a la voluntad de infundir la simetría geométrica como expresión de un anhelo hacia la perfección, se engarza el poder, la presencia de una hegemonía que hace de la ciudad el locus por excelencia de la producción y circulación de un orden social y político. De allí que, al nivel concreto de los diferentes lugares y edificios de la ciudad, lo arquitectónico aloje también en sus muros un conjunto ideológico. Este enlace de la arquitectura y la ideología oculta [...] una densidad constituida por una serie de privilegios y prohibiciones que darían, en primera instancia, un significado único: la división entre ricos y pobres, entre poderosos y subalternos, entre hombres, mujeres y homosexuales. (Guerra)

Guerra establece que la distribución física y simbólica del poder en la urbe es transgredida por el tránsito de los excluidos. El vagabundo que incursiona en los llamados barrios altos, el indígena que vende sus mercaderías en el centro o la prostituta que

Revista Iberoamericana, Vol. LXXXI, Núm. 250, Enero-Marzo 2015, 233-251 ISSN 0034-9631 (Impreso) 
ofrece su cuerpo en las zonas residenciales: “[...] no sólo producen una interrupción en ese orden sino que también resquebrajan las paredes de ese significado único haciendo del territorio urbano, un espacio de simultaneidades raciales, sociales y genéricas que corren a la par de las jerarquías impuestas por el grupo hegemónico" (Guerra). A partir de ello, se puede establecer que la ciudad es un espacio móvil que constantemente se está resignificando a partir de sujetos urbanos que miran, atraviesan y recorren la urbe interviniéndola y que, a la postre, reinventan y redicen desde su propia subjetividad.

Néstor Perlongher hace, por otra parte, una lúcida lectura de la circulación de cuerpos en San Pablo, estableciendo que las calles de la megalópolis brasileña se transforman en algo más que un mero lugar de tránsito o de fascinación consumista, se revelan como "[...] un lugar de circulación deseante, de errancia sexual. Prostitutas y "entendidos" exploran, entre otros flaneurs libertinos, las posibilidades libidinales del flujo de las masas en la metrópolis" (Perlonguer 46). Así, frente la distribución física y simbólica del poder se levanta una "territorialidad perversa":

[...] que la transgresión instaura, pero que no es un mero reverso perverso de la ley: categorizaciones vagas, fluidas, superpuestas, cada una de ellas actuando como "operadores de intensidad libidinal": territorialidad itinerante, legible en las redes de circulaciones y encuentros entre los cuerpos que, en alas del deseo, deambulan: territorialidad oscura, que instala en el corazón de la noche su esplendor patético, la trama de sus secretos y sus escondites: territorialidad nómade: en las derivas de los noctámbulos, en los vagabundeos del sexo y de la droga, en los turbios ilegalismos tramados en las madrugadas [...]. (Perlongher 50)

El devenir de la Mariana por las calles de Buenos Aires puede situarse dentro de esa "territorialidad perversa". No sólo por una errancia sexual que, dada su condición de "gato", apunta al intercambio de su cuerpo por una compensación económica sino porque su propia forma de desplazarse, con un cubo de cocaína entre sus piernas, se levanta como una transgresión itinerante del orden establecido: "Practicó el ejercicio de mover por dentro: el paquete parecía seguro en su lugar y sintió un cosquilleo de placer, esta vez bien abajo, difundiéndose hacia las piernas" (Fogwill, Vivir afuera 60). La prevención comercial y el desenfreno erótico se anudan en la peregrina práctica de Mariana, constituyendo una transgresión al orden de la ciudad. La "gato" levanta una "territorialidad perversa" en medio de la estructura de poder de la capital argentina. Wolff, Pichi, Susi, entre otros, son movidos, también, por una pulsión que los lleva a resemantizar el espacio urbano.

No es casual que Fogwill comience la narración en plena noche porteña. Los ambientes nocturnos privilegian y estimulan la irrupción de la sexualidad del margen. De allí que la mayoría de los encuentros eróticos de la novela se sitúen en medio de la oscuridad, llevando a los personajes a gozar de una sexualidad abierta:

Revista Iberoamericana, Vol. LXXXI, Núm. 250, Enero-Marzo 2015, 233-251 ISSN 0034-9631 (Impreso)

ISSN 2154-4794 (Electrónico) 
Cierta pulsión nómade se abre paso por los instersticios de la ciudad. Estos impulsos no suelen manifestarse abiertamente a la luz del día. Es preciso buscarlos no en la centralidad resplandeciente de la urbe sino en los brillos opacos del margen, en los devaneos a través de la noche donde instauran, siempre precariamente, el encanto de su misterio, aduares transparentes que casi consiguen mantenerse en secreto.(Perlongher 45)

La reflexión de Prosa plebeya es clave para comprender las desatadas puestas en escena nocturnas de Pichi y Susi en un motel, el ardiente encuentro del gordo homosexual y el tucumano en una pensión perdida o el desenfreno de Saúl y Diana es su departamento. Un Buenos Aires nocturno es el espacio ideal para la irrupción de la "erótica letal" de la novela. Incluso en el único encuentro que se da a plena luz del día, la pequeña orgía protagonizada por Wolff, Cecilia, Mariana y Saúl, es la oscuridad la que prima en la escena al situar a los personajes en un espacio cerrado, privado y oculto: el departamento de Wolff.

En Vivir afuera los personajes actúan en el margen y a contrapelo de la "gilada". Mientras "la gilada" duerme o trabaja los hombres y mujeres de Fogwill beben, se drogan, trafican y "aprietan". Fogwill construye un relato situado en el tiempo sagrado de la fiesta. Los malos aires de Fogwill se levantan afuera de todo orden u convención social.

\section{UNA ERÓTICA SIN FIN}

Vivir afuera pone en juego una erótica ilimitada. Fogwill aborda en su novela las más variadas posibilidades de exploración y degustación de los cuerpos incorporando una serie de posibilidades que habían sido soslayadas o infravaloradas por la narrativa hispanoamericana. Para esto, el escritor argentino sigue los trayectos de siete personajes que, sin excepción alguna, se sumen en los delirios de la carne. A ello Fogwill suma la revelación de sus deseos ocultos, sus evocaciones y sus alusiones a otras historias de corte sexual, lo que, a la postre, nos sitúa frente a un texto que multiplica exponencialmente las líneas de representación del fenómeno erótico.

Mariana y Wolff explotan, a todas luces, una erótica ilimitada. Luego de un azaroso encuentro en un café porteño, la pareja se irá al departamento del Wolff donde realizarán una serie de juegos sexuales que, además, estarán aderezados por la presencia del alcohol y la cocaína, lo que terminará estimulando la degustación de la piel:

Wolff sorbió un trago de cerveza helada y se inclinó para apoyar sus labios contra la boca que ella ofrecía, abriéndola exageradamente para mostrar los labios estirados y húmedos de saliva viscosa [...] Ella sintió que al cabo de la invasión de un chorro de cerveza la lengua hurgaba entre sus dientes y sus encías, a la busca de piedritas de coca. (Fogwill, Vivir afuera 121-122)

Revista Iberoamericana, Vol. LXXXI, Núm. 250, Enero-Marzo 2015, 233-251 ISSN 0034-9631 (Impreso) 
Lo interesante de Mariana y Wolff es que, luego de su encuentro erótico, se abrirán a experimentar con los cuerpos de Saúl y Cecilia, poniendo con ello término a su extrema jornada bonaerense. Ahora bien, el trayecto sexual de Mariana y Wolffes complementado por la serie de historias que serán evocadas por ambos. Uno de los relatos más atractivos, en esta dirección, es el "trabajo" que Mariana desarrolla para un par de oficiales de la policía, quienes le proponen sacarle información a unos "locos" a cambio del dinero. Antes de formular la propuesta, los oficiales "seducirán" a la prostituta argentina:

[...] antes de empezar a explicarme lo que pretendian uno de los tipos empieza a tocarme el pelo y a mí ese tipo no me gustaba nada. Yen cambio, la manera de mirarnos del otro me calentó porque ése si era más joven y tenía su pinta. Ahi yo tratando de zafar les digo que estaban por llegar mis viejos pero el más viejo me dice que los vio esperando el micro en el puente de Calchaqui y que seguro iban a tardar y ahi se ponen a tocarme entre los dos y a sacarme las ropa y te cuento que el de más pinta se bajó el pantalón y me la metió de una: con corbata, camisa y saco puestos y con el pantalón y los calzones con florcitas caídos a la altura de los tobillos el otro, el que empezó primero a tocarme, se sentó a mirar [...] Adentro me acabó el flaco y yo acabé como una loca [...]. (Fogwill, Vivir afuera 108-109)

Mariana se interna en una quinta de evangélicos para obtener de los "locos" el paradero del dinero que obtuvieron producto de una serie de operaciones ilegales. Pese a que la quinta es un lugar donde está prohibido el contacto sexual, Mariana conocerá los encuentros homoeróticos de dos mujeres: "Las dos semanas que estuve yo expulsaron a dos tipas que estaban yéndose todas las noches a apretar a la cocina. Eran tortas" (Fogwill, Vivir afuera 111). Asimismo, protagonizará un extenso ménage à trois en un motel:

Entonces los junto a los dos y les digo que a mí me pasaba una cosa con los dos [...] Que era así y que nos piráramos los tres juntos... Te la hago corta: nos fuimos a un telo de la ruta y nos pasamos dos días enteros de pico, tomando birra-cerveza-y comiendo nada más jamón, queso y pebetes... [...] los locos ni idea tenían de lo que habían tomado y morfado ni de cuántos días llevábamos conchabados en esa pieza meta sauna, cerveza, pico y tracatraca: ponele que me echaron mil polvos. (Fogwill, Vivir afuera 133-134)

Wolff cuenta, por su parte, la serie de historias que tuvo con distintas amantes. Entre ellas destaca la obsesión que le despierta la mujer de un ex ministro que acaba de tener un bebé: "[...] al final me dice que no se acostaba con nadie porque acababa de tener un bebé... Y ahí me volví loco... Me calenté como nunca en la vida... Pensé que ella tenía olor a bebé... ¡O a leche! En realidad tenía todavía leche y yo se la chupé..." (Fogwill, Vivir afuera 153). El relato más extremo referido por Wolff tiene que ver con las prácticas zoofílicas que realiza una de sus amantes:

Revista Iberoamericana, Vol. LXXXI, Núm. 250, Enero-Marzo 2015, 233-251 ISSN 0034-9631 (Impreso)

ISSN 2154-4794 (Electrónico) 
Pero un día me empieza a hablar de los caballos... La familia tenía caballos en Pilar... Y me cuenta que tenía un primo gay y que cuando eran chicos iban a la caballeriza y entre los dos les hacían la paja a los potrillos... No... A los petizos de polo, creo... Eso me calentó y no te cuento cuando me contó que ella sabía hacer que los petizos sacaran la poronga hacia atrás, por debajo de la cola y que ella se la apoyaba entre las piernas... Debía ser entre las barandas del corral y entre las piernas de ella... Y allí ella se pajeaba y lo pajeaba al caballo... (Fogwill, Vivir afuera 155)

Fogwill explota un amplio y variado espectro de posibilidades del eros en Vivir afuera. Los cursos de acción de Wolff y Mariana son concluyentes en este sentido. Lo anterior, es extensivo para Saúl, Diana, Cecilia, Pichi, Susi y cada uno de los personajes secundarios que intervienen en la novela, todos los que parecen movidos por un intenso deseo de vivir la vida hasta el extremo. En este sentido, la novela pueda ser comprendida a partir de la relectura del concepto de "pulsión de muerte" propuesta por Slavoj Žižek en Visión de paralaje. Para Žižek la "pulsión de muerte" se relaciona con la búsqueda de un exceso que no soporta y que desprecia el curso ordinario de las cosas. Žižek sostiene que la pulsión de muerte freudiana es, pese a que su nombre se lo da su contrario, la búsqueda de un exceso de vida: "La lección definitiva del psicoanálisis es que la vida humana nunca es 'sólo vida': los humanos no estamos simplemente vivos, estamos poseídos por la extraña pulsión a disfrutar de la vida en exceso, apegados apasionadamente a un exceso que no soporta y que desprecia el curso ordinario de las cosas" (Žižek 105).

La "pulsión de muerte" explica la extrema forma de vivir que tienen los personajes de Vivir afuera. No por nada Wolff y Mariana, en tan solo once horas, escenifican un erotismo que acaricia a la muerte, consumen en reiteradas ocasiones cocaína y alcohol y evitan dormir. El sueño parece simbolizar para Fogwill el poder de la muerte que debe ser transgredido. Así puede ser comprendida, también, la relación que mantiene Pichi con Susi, los cuales se recluyen en un motel para dar rienda suelta a la pasión que los une. Pichi y Susi combinan mariguana y alcohol en una serie de prácticas sadomasoquistas:

-Ay me caliento Pichi... ¡Ponémela!

-Ahí la tenés...

$-¡$ iRompeme toda!

-A mí rómpeme todo vos... ¡Clavame la uña ahí!

-¿Dónde ahí?

-Ahí en la pija...

-[...] ¡Pegame Pichi! ¡Durá y aguantá más!

-Ahí el cuchillo... ¡Con el cuchillo! Con la punta apenas... ¡Aquí!

-¿Dónde? ¡Decime! ¿Ahí?

-¡En el hombro clavame! (Fogwill, Vivir afuera 161-162)

Revista Iberoamericana, Vol. LXXXI, Núm. 250, Enero-Marzo 2015, 233-251 ISSN 0034-9631 (Impreso)

ISSN 2154-4794 (Electrónico) 
Pichi y Susi asumen un erotismo radical que usa el sufrimiento como una forma de expandir las alternativas del eros. Ejecutan prácticas sadomasoquistas (S/M) que se ubican en los límites del erotismo aceptable. Jeffrey Weeks sostiene que la política del $\mathrm{S} / \mathrm{M}$ se destaca por una subjetividad puesta en el significado de la situación, tal como la ven sus practicantes; y por su énfasis en la elección, en el derecho a involucrarse en situaciones extremas para obtener placer. La subjetividad y la elección se implican mutuamente pues el $\mathrm{S} / \mathrm{M}$ es válido en situaciones de consenso entre iguales donde la erotización ritualista del deseo de sufrimiento, las diferencias de poder como significantes del deseo y la realización de fantasías prohibidas son vías para alcanzar el placer. Bajo esta lógica, se sitúa el juego con la degradación utilizado por los amantes argentinos al representar el uso y el abuso del poder como una forma de estimular el fenómeno erótico.

Fogwill construye une erótica ilimitada que tiende a transgredir, constantemente, los tabúes hispanoamericanos, investigando, en consecuencia, las más variadas manifestaciones del eros. La heterosexualidad, la homosexualidad, la masturbación, el sadomasoquismo, las relaciones sexuales en público, la zoofilia son algunas de las variables recogidas por el autor argentino. Vivir afuera no se limita a insinuar o a dar a entender la irrupción del erotismo sino que apunta a construir un discurso obsceno en términos que, todo aquello que debería quedar fuera de escena, es decir, aquellas prácticas sobre las cuales la narrativa regional corrió un tupido velo, son narradas por el autor de Los Pichiciegos. Así, plasma explícitamente el autoerotismo de Susi al inicio de la novela:

Tiene el impulso de llevarse a la boca el dedo índice para mojarlo, palpar su pecho izquierdo y cuando roza el pezón reconoce sus bolitas de carne dura y las acaricia con las yemas secas pensando en los ojos de rabia de Mariana, y en la imagen del Pichi [...] se destraba la hebilla del cinturón, desprende el botón del jean, y hace bajar despacio el cierre de su bragueta [...]. (Fogwill, Vivir afuera 19-20)

Ahora bien, la tesis central de este artículo tiene que ver con reconocer en la novela una "erótica letal" que corre al borde del abismo. La desenfrenada lubricidad de los personajes que cruzan la novela los lleva a asumir prácticas riesgosas. El gordo homosexual que se autocalifica como el "judío errante" elige, en este sentido, una sexualidad que adolece de cualquier clase de restricción. Lo anterior, queda en evidencia al considerar el inesperado y amenazante encuentro con el tucumano durante velorio de su padre:

En su mezcla milagrosa de fugazzas y isui-sidas!, adiviné la pija del tucumano y no volvi al velorio, ni a mi hogar, y en cambio me quité los zapatos para entrar sin hacer ningún ruido en la pensión del tucumano, donde se la chupé toda la noche, donde me la metió toda la noche, y donde me pidió, trémulo y empapado de sudor, que yo también se la metiera a él... Y así fue: se la puse como en un sueño de pizzería Atacama, y

Revista Iberoamericana, Vol. LXXXI, Núm. 250, Enero-Marzo 2015, 233-251 ISSN 0034-9631 (Impreso)

ISSN 2154-4794 (Electrónico) 
ambos, como en un sueño, llegamos juntos al éxtasis del amor [...]. (Fogwill, Vivir afuera 202-203)

El "judío errante" asume una postura de vida que contraviene la primacía de la seguridad, el control y los resguardos sexuales propios de la irrupción del SIDA. Béatrice Bantman propone en Breve historia del sexo que la aparición del VIH genera una "ola de abstinencia" sexual en las décadas de 1980 y 1990 que marca un quiebre con las gozosas décadas previas: "El miedo, seguido de cerca por la apatía, parece haber acabado con los alegres placeres y nos han dejado sin el estado de ánimo de los años sesenta y setenta" (Bantman 178). Fogwill hace circular al "judío errante" a contrapelo de la forma de entender la sexualidad a fines del siglo XX.

[...] yo soy el judio errante, soy un error flotante en un barrio de tango, de fango, de costureras con zuecos que se arrastran pajizas como en un cuadro de Van Gogh. Pero, ahora, les ruego sepan disculparme porque debo partir: voy a morir de sida. $Y$ a este encuentro de amor no hay pija tucumana que pueda hacer llegar ni un minuto después. (Fogwill, Vivir afuera 203)

El "judío errante" demuestra una actitud que busca el exceso más allá de los límites propios de la muerte, dando forma a una erótica letal que sólo puede ser asumida como un fenómeno extremo. En cualquier caso, el "judío errante" no es el único personaje que sigue esta línea. Hay otros que deambulan en la desmesura de una erótica sin fin.

\section{"RULETA RUSA SEXUAL"}

Vivir afuera radicaliza los postulados sobre el erotismo de Georges Bataille. En la novela de Fogwill no se trata de que el erotismo sea, simplemente, "[...] la aprobación de la vida hasta en la muerte" (Bataille 13), estableciendo una suerte de vínculo entre la idea de continuidad y discontinuidad presente en la muerte y el erotismo, sino que el escritor argentino da forma a un "erotismo letal". Los encuentros sexuales de Mariana, Wolff y Saúl extreman los alcances del texto publicado por el teórico francés en la década de 1950.

Para Bataille el terreno del erotismo es "[...] esencialmente el terreno de la violencia" (Bataille 21) y, en las fronteras de la violencia, no hay nada más violento que la muerte. Bajo esta lógica, se entienden las prohibiciones que se levantaron sobre la actividad sexual. Ahora bien, Bataille reflexiona sobre una escena erótica que desconoce la amenaza del VIH y, en consecuencia, no advierte la ominosa unión que la muerte establecerá con el sexo a partir de 1980. Contraviniendo las percepciones médicas, culturales y simbólicas trazadas sobre el tratamiento de la enfermedad, Fogwill vincula sexualmente a Mariana, infectada de SIDA, con Wolff y Saúl, los que, a pesar de conocer la enfermedad de la

Revista Iberoamericana, Vol. LXXXI, Núm. 250, Enero-Marzo 2015, 233-251 ISSN 0034-9631 (Impreso) 
prostituta, mantendrán encuentros eróticos con ella. De esta forma, Wolff y Saúl no sólo aprobarán el erotismo hasta en la muerte sino que jugarán una "ruleta rusa sexual" que podría llevarlos a contraer la enfermedad y, por cierto, los efectos mortales del SIDA.

La seducción de la sangre es uno de los elementos que explica las determinaciones de Wolff y Saúl. La sangre se ha vinculado tanto con la vida como con la muerte. Isabel Monzón sostiene que los cristianos consideran que la sangre simboliza la vida misma: "[...] la sangre que fluye de las llagas de Cristo y que se recoge en el grial es el brebaje de la inmortalidad [...] Para la Biblia la sangre evoca la muerte pero también es la vida" (Monzón 56-57). Asimismo, no se puede soslayar que la sangre representa el calor corporal y, en esta línea, es considerada como un vehículo de las pasiones. La pasión de la sangre es evocada por Saúl al rememorar el vínculo erótico que mantiene con una antigua amante:

Contaba que su primera amante, una asistente de cátedra bastante mayor, había descubierto la atracción que sentía por la sangre. Por entonces,-antes de la epidemia-cuando hacían el amor se extraían sangre mutuamente con jeringas de cien centímetros cúbicos, la bebían, y después, besándose, mezclaban sus sangres y se la pasaban de una boca a la otra mezcladas con saliva. (Fogwill, Vivir afuera 79-80)

La sangre genera tal nivel de deseo en Saúl que ni siquiera la presencia de un arraigado tabú en occidente, la sangre menstrual, lo aleja de su avidez por el líquido vital. Bataille considera que la sangre menstrual es una manifestación de la violencia interna que cae dentro del ámbito común de la porquería y la corrupción. Para Saúl tiene nula importancia esa prohibición en el noviazgo que mantiene con Diana:

[...] habían estado cuatro horas juntos y casi todo el tiempo él había estado penetrándola, o jugando con su sexo [...] Habían comido en la cama, él había tomado vino y hasta aceptó uno de sus Marlboro y, como otras veces en que ella menstruaba, en un momento se untó la cara y un rato después había prendido la luz: el semen y la sangre seca distribuidos con bastante uniformidad por las mejillas, la nariz y la frente parecían el maquillaje de un payaso [...] a él lo excitaba la sangre. (Fogwill, Vivir afuera 79)

Al borde de los sesenta años, Wolff tiene una postura de vida que sólo le da importancia al dinero y la carne. Ambos factores son determinantes en su vida. Con relación a su gusto por la carne, hay un diálogo iluminador con Mariana:

-La verdad es que estás ahí en la alfombra, medio en bolas y contás algo... y cuando respiras para apurarte, o para hablar más fuerte o cambiar la voz para contar lo que dice el otro, se te mueven las tetas y se te hincha abajo [...] yo que sé. ¡Ésa es la verdad...! Ésa es la verdad... Que contás bien!

-O sea que me das la razón: loúnico que te interesa es la carne.(Fogwill, Vivir afuera 152)

Revista Iberoamericana, Vol. LXXXI, Núm. 250, Enero-Marzo 2015, 233-251 
El deseo por la carne de Wolff se conecta con el concepto homónimo planteado por Bataille, el que establece que la carne es la experiencia de un estallido, la violencia que irrumpe en el momento en que se desencadena el deseo: "El movimiento de la carne excede un límite en ausencia de la voluntad. La carne es en nosotros ese exceso que se opone a la ley de la decencia" (Bataille 97-98). Wolff se sume en un exceso que puede representar una potencial amenaza para su vida, sin embargo, el placer de cruzar los límites es mucho más fuerte que las consideraciones racionales que puede o no tener su vínculo con Mariana.

-iAhora yo te la voy a chupar...!

_Cortala loco... ¿Te dije que puedo tener el sida...?

-No trago saliva... Dale. Vení... [...] Dejame un poco... Dos minutos [...]

-Estás reloco... Es por la frula ésta... ¡Te pegó mal!

-Es por el olor... Por las ganas...

-¿De qué? ¿En serio querías chupármela?

-De morderte...Morderte hasta hacerte sangrar toda la concha... (Fogwill, Vivir afuera 156)

La salvaje transgresión de Wolff y Saúl adquiere mayor relevancia al considerar el tratamiento que el propio Fogwill realiza del SIDA al inicio de la novela. Fogwill recoge la percepción popular que se levantó sobre la enfermedad en la décadas de 1980 y 1990, décadas marcadas por el desconocimiento y los prejuicios que generó el VIH en América Latina. Al inicio de Vivir afuera, Pichi mantiene una fuerte discusión con Susi a raíz de su deseo de tener relaciones sexuales con ella a pesar de que ésta acababa de realizarse un aborto: "[...] y le gritó que fuera a apretar con la Mariana, que le daba permiso para encamarse con cualquiera pero que a ella la dejara en paz. El Pichi no reaccionó, se puso suave y dijo que Mariana no le gustaba y que, además, estaba podrida: -Tiene la pudrición total" (Fogwill, Vivir afuera 23). La afirmación de Pichi se entronca con la reacción inicial que provocó el VIH, generando una simbólica que asoció la enfermedad con la descomposición de la vida. Asimismo, se vincula con lo que Susan Sontag denominó como la muerte simbólica de la enfermedad, es decir, que el SIDA significa una muerte social anterior a la muerte física:

Tal como la enfermedad es la mayor de las miserias, así la mayor miseria de la enfermedad es la soledad que tiene lugar cuando la naturaleza infecciosa de la enfermedad disuade de acudir a quienes han de asistir; cuando hasta el Médico apenas se atreve a venir... se trata entonces de una proscripción, de una Excomunión del paciente... (Sontag 40-41)

Sontag parte de la base que los mitos y las metáforas matan y, en el caso del SIDA, además de los síntomas, malestares y padecimientos propios de la enfermedad, los pacientes deben enfrentar la condena social que supone contraer un virus asociado a

Revista Iberoamericana, Vol. LXXXI, Núm. 250, Enero-Marzo 2015, 233-251 ISSN 0034-9631 (Impreso)

ISSN 2154-4794 (Electrónico) 
fuertes componentes simbólicos: “[...] tener sida es precisamente ponerse en evidencia como un miembro de algún 'grupo de riesgo', de una comunidad de parias. La enfermedad hace brotar una identidad que podría haber permanecido oculta para los vecinos, los compañeros de trabajo, la familia, los amigos" (Sontag 31). Sontag establece, en esta línea, que sobre los enfermos de sida pesa una condena moral, dado que, tradicionalmente, es considerada como "[...] una calamidad que uno mismo se ha buscado, merece un juicio mucho más severo que otras vías de transmisión -en particular porque se entiende que el SIDA es una enfermedad debido no sólo al exceso sexual sino a la perversión sexual" (Sontag 33). Para Sontag el SIDA convierte en promiscuo todo acto sexual a excepción del sexo monogámico: “[...] el miedo a la sexualidad es el nuevo registro del universo de miedos en que vivimos hoy todos [...] ahora existe el miedo a contaminar al prójimo, un miedo inevitable infundido por la angustia del SIDA" (Sontag 78-79). De ahí que Mariana sienta pavor frente a la posibilidad de contagiar a otros con la enfermedad: "Es de terror tener el sida y contagiar. No por mí... Lo que tengo terror es de contagiar... Un día soñé que contagiaba a un viejo y que la policía venía a buscarme y me encerraban en un convento" (Fogwill, Vivir afuera 159). El SIDA constituye una enfermedad que no sólo aterra por el padecimiento en sí mismo sino por la degradación social que experimenta al paciente. En Vivir afuera Mariana hace un crudo retrato del significado de la enfermedad:

Mira tío, lo único que me interesa es la falopa y pasarla rebién, hago gatos porque no tengo guita, pero si tengo guita, más ganas me vienen de meterme a un boliche así y levantarme un punto. Me llamo María Eva pero la verdad que todos me dicen Mariana y que los giles me pongan el nombre que más ganas les dé. Tengo la pudrición total pero me cuido. Yo no me encamo con la regla ni cuando me está por bajar, me tomo toda la leche en la garganta, pero nunca lastime a nadie y me cuido los dientes y las encías. Lo único que me interesa es pasar bien los años que me quedan. (Fogwill, Vivir afuera 96)

Mariana debe enfrentar la marginación social que ya anticipaba Pichi al afirmar que no se acostaría con ella porque posee la "pudrición total". Sin embargo, el encuentro de Mariana con Wolff, primero, y con Saúl, después, pondrá de manifiesto un efecto distinto al propuesto por Sontag. Lejos de generar rechazo en Wolff, el SIDA se convierte en una verdadera invitación a anudar las hebras que conectan el erotismo y la muerte:

- ¿Si fuera cierto? ¿Si veo el análisis y todo eso...? -preguntó Wolff para mostrarse más interesado.

-Ponele que sí: ponele que te muestro un papel firmado por la Fundación Vida. ¿Qué harías?

-La verdad es que me calentaría... En realidad me estoy empezando a calentar... (Fogwill, Vivir afuera 152-153)

Revista Iberoamericana, Vol. LXXXI, Núm. 250, Enero-Marzo 2015, 233-251 ISSN 0034-9631 (Impreso)

ISSN 2154-4794 (Electrónico) 
El encuentro de Mariana, Wolff y Saúl se entronca con una práctica orgiástica que comienza a desarrollarse en Estados Unidos en la década de 1990 y en España e Hispanoamérica en la década siguiente: la "ruleta rusa sexual". Se trata de orgías en las que los participantes no utilizan protección alguna y en la que uno de los participantes tiene el VIH. La "ruleta rusa sexual" es una tendencia que apunta a mantener experiencias sexuales límites que no sólo implican una enorme carga de placer sino una mayor conexión con sus esporádicas parejas. Así, ésta puede ser leída a partir de la conexión que se produce entre transgresión y voluptuosidad en la medida que entre mayor sea el horror, más profunda es la alegría de la superación de ese límite: "Se da el caso de que, sin la evidencia de una transgresión, ya no experimentamos ese sentimiento de libertad que exige la plenitud del goce sexual. De tal manera que, a veces, al espíritu hastiado le es necesaria una situación escabrosa para acceder al reflejo del goce final" (Bataille 113). Saúl y Wolf alcanzan un horror que, en ningún caso, podía ser anticipado por Bataille. Lejos de la amenaza que suponía la sífilis o la gonorrea, el SIDA es una enfermedad letal y, en consecuencia, el riesgo asumido por ambos es considerable. Más aun a fines de la década de 1990, época en que el tratamiento de la enfermedad era mucho menos efectivo que en la actualidad.

La actitud de Woll frente a la enfermedad se explica no sólo por su predilección por la carne. A ello hay que sumar un desencanto vital que lo insta a asumir toda clase de riesgos. Wolff piensa que se encuentra en la última parte de su vida, que la muerte es una amenaza real y que, en consecuencia, no tiene la menor importancia exponerse a distintas clases de peligros. Así, se abre a vivir una experiencia que supera los límites de la "ruleta rusa sexual" dado que tiene plena certeza de que Mariana está contagiada:

-¿Querés metérmela...?

-Si... En seguida...

- ¿Se puede gritar?

-Si... Gritá.

-Voy a acabar.... ¡Metémela y acabo...!

-¡Ahí la tenés...! ¡Pasame cervecita!

-Sos una mente podrida... ¡Puto...!

-[...] Aquí te va a doler más...Voy a acabar...

No me hablés más... Basta. ¡Haceme todo lo que quieras pero callate! (Fogwill, Vivir afuera 157)

Fogwill no hace ninguna mención a la posible utilización de preservativos por parte de Wolff y, dado el nivel de excitación y ardor de la pareja, lo más probable es que el "negociante" argentino no haya utilizado ninguna clase de protección. Hay unos versos que Wolff le escribe a Mariana que pueden explicar su deseo hacia la "gato" argentina: “"Mariana está podrida De sí De sida Morirá Como todos Morirá sin amor Pero antes Devoraré Un pedazo De su cuerpo Sangrante Amado"” (Fogwill, Vivir afuera 235).

Revista Iberoamericana, Vol. LXXXI, Núm. 250, Enero-Marzo 2015, 233-251 ISSN 0034-9631 (Impreso) 
A raíz de una amenaza de bomba que se produce en el centro medico donde trabajan Saúl y Cecilia, al que han llegado Wolff y Mariana para un control de la portadora del $\mathrm{VIH}$, las consultas son suspendidas, lo que motiva su salida a un bar que se encuentra en las cercanías del hospital. Allí se dará una trivial conversación en la que Mariana propondrá que sigan el encuentro en la casa de Wolff, lo que para éste tiene una serie de reminiscencias de la década de 1960:

Estos son los años sesenta... No:-se corrigió-fue en los setenta y durante años la escena seguía repitiéndose: había un lugar, gente que se agrupaba creyendo que solamente los unía el azar, una mesa o dos mesas que terminaban acoplándose, pasaban las personas, pasaban los minutos sin dejar huella y se cumplían horas hasta que alguien, aburrido, proponía que fueses a una casa, "a mi casa" - decía- o "a tu casa". Y ahora esta mina, que por entonces ni había nacido, repite aquella escena. (Fogwill, Vivir afuera 271)

Las remembranzas de Wolff son relevantes para preparar un escenario en que los cuatro amantes viven no en los términos del miedo de la década de 1990 sino bajo el alero de la libertad y la experimentación propia de la década de 1970. De hecho, mientras Cecilia se acuesta con Wolff, Mariana lo hará con Saúl. La apreciación de Cecilia es contundente:

Buscando soda o una botella de agua mineral en la cocina se alcanza a ver los sillones del living y el humo del cigarrillo de ella y un brazo de Saúl caído al costado del sillón. [...] Ojalá hayan usado forro. Es tan forro y está tan loco que es capaz de hacer experimentos. [...] Me miran. Ella sí seguro que miró para aquí y me vio con las tetas al aire. Si llega a hablarme o a gritar, me voy en bolas a pedirle un Marlboro. Si le cuento al viejo que Saúl está en bolas se vuelve a calentar. Si les cuento a las minas del hospital que me encamé con un viejo de cerca de sesenta más viejo que mi viejo y que hice más quilombo cuando acababa la segunda vez para que Saúl oyera y se calentara y les cuento que los vi en bolas a él y a una paciente portadora se arma el quilombo del año. (Fogwill, Vivir afuera 283)

La actitud de Saúl es atractiva en la medida que, por su condición de experto en VIH, tiene claro cuáles son los riesgos de mantener un encuentro erótico con Mariana. Más llamativo aun es la vacilación que exhibe Cecilia respecto de si Saúl habría ocupado o no un preservativo, lo que, al igual que el vínculo de Wolff con Mariana, supone una total transgresión a los límites que impone el tratamiento del SIDA. Es más, Cecilia insinúa aun que habrían hecho un intercambio de parejas en el departamento de Wolff: "¿Y si llego a decirles que el viejo tenía cuarenta, que se tiraban ondas con Saúl y que después de hacer la cambiada ellos estuvieron a punto de...?” (Fogwill, Vivir afuera 285).

Fogwill proyecta, en definitiva, un tratamiento del erotismo en medio de la sombra dantesca del SIDA, que invierte, transgrede y rompe con la sexualidad controlada e

Revista Iberoamericana, Vol. LXXXI, Núm. 250, Enero-Marzo 2015,233-251 ISSN 0034-9631 (Impreso)

ISSN 2154-4794 (Electrónico) 
incluso la abstinencia que se había apoderado del desarrollo del erotismo 1990. Vivir afuera plasma un erotismo radical que da cuenta de una liberalización de la sexualidad y de la búsqueda de un goce que se alza como una aspiración irrenunciable de los personajes que cruzan el gran Buenos Aires a fines de la década de 1990.

\section{Placer en el ABismo}

Vivir afuera evoca la visión que tiene Rilke sobre el surgimiento de las obras de arte. En una carta que le envía a su esposa sostiene que: "Las obras de arte nacen siempre de quien ha afrontado el peligro, de quien ha ido hasta el extremo de una experiencia, hasta el punto que ningún humano puede rebasar" (Bachelard 278). Más allá de las experiencias vitales que pudieron o no gatillar la construcción de la novela, la expresión de Rilke resulta interesante debido a que el relato de Fogwill llega hasta un extremo en las letras hispanoamericanas, supera los limites de la forma de representar y simbolizar el erotismo, vive afuera de las normas y la convenciones que rigieron la narrativa continental hasta la irrupción de la obra de Cortázar.

Vivir afuera se sumerge en la intimidad de siete personajes que gozan, padecen y rememoran las más variadas formas de ejecutar el erotismo, radicalizando, en este sentido, el trabajo que distintos autores argentinos habían desarrollado desde la década de 1960. La novela de Fogwill expone salvajemente el encuentro, la indagación y la fusión de la piel en los malos aires argentinos. El punto de ebullición de Vivir afuera se encuentra en la escena situada en el departamento de Wolff, dado que éste junto a Saúl extreman la "ruleta rusa sexual" al penetrar el cuerpo infectado de Mariana, materializando una erótica letal que contraviene las convenciones sociales, éticas y salubres elaboradas sobre el SIDA.

Ante la pregunta de si Vivir afuera era o no la mejor novela argentina de los noventa, Fogwill respondió lo siguiente: "No creo, ojalá. Puede ser una novela importante del dos mil y pico" (Munaro). Luego del relativo silencio con que circularon sus textos, parece que por fin el autor de Los Pichiciegos comienza a obtener el reconocimiento que merece una obra de excepción. Y dentro de esa destacada producción narrativa, Vivir afuera es la pieza más destacada de una propuesta que no sólo debe ser considerada como la gran novela argentina de los noventa sino, sobre todo, como un relato que abre nuevas rutas literarias y eróticas por las que transitará la novela hispanoamericana del siglo XXI. 


\section{BiBLIOGRAFÍA}

Bachelard, Gastón. La poética del espacio. Ernestina de Champourcin, trad. México: Fondo de Cultura Económica, 1965.

Bantman, Béatrice. Breve historia del sexo. Barcelona: Paidós, 1998.

Bataille, Georges, El Erotismo. Antoni Vicens y Marie Paule Sarazin, trads. Barcelona: Tusquets editores, 1997.

Becerra, Juan. "Historias del otro lado". $<$ http://www.fogwill.com.ar/critica.html\#link>. 14 agosto 2012.

Cristal, Martín. "Diez años de Vivir afuera". El pez volador. 26 ago. 208. <http:// elpezvolador.wordpress.com/2008/08/26/diez-anos-de-vvir-afuera/>. 14 ago. 2012. Fogwill, Rodolfo. Los Pichiciegos. Buenos Aires: El Ateneo, 2010. Vivir afuera. Buenos Aires: Editorial Sudamericana, 1998.

Gallardo, Mario. “Memorias, erotismo y arte poética en los almanaques de Julio Cortázar”. Revista de Letras. 25 enero 2009. <http://www.revistadeletras.net/memoriaserotismo-y-arte-poetica-en-los-almanaques-de-juliocortazar/>. 13 abril 2011.

Guerra Cunningham, Lucía. "Género y Ciudad: Imaginarios urbanos en la narrativa Latinoamericana”. <http://es.scribd.com/doc/24396574/GUERRACUNNINGHAM-Lucia-genero-y-ciudad-imaginarios-urbanos-en-la-narrativalatinoamericana>. 16 agosto 2012.

Gundermann, Christian. "Julio Cortázar: literatura y revolución”. El diván. 7 marzo 2008. <http://blogs.periodistadigital.com/eldivan.php/2008/03/07/julio-cortazarliteratura-y-revolucion>. 13 abril 2011.

Link, Daniel. "Seis personajes en busca de autor". <http://www.fogwill.com.ar/critica. html\#link>. 14 agosto 2012.

López, Martina. "La narración de los cuerpos". Historia crítica de la literatura Argentina. Elsa Drucaroff, ed. Buenos Aires: Emecé Editores, 2000. 183-215.

Marcuse, Herbert. Eros y civilización. Juan García, trad. Barcelona: Editorial Ariel, 2008.

Monzón, Isabel. Báthory. Acercamiento al mito de la Condesa Sangrienta. <www. isabelmonzon.com.ar>. 10 sept. 2008.

Munaro, Augusto. "Entrevista a Fogwill por la reedición de "Vivir afuera", $<$ http:// asesinostimidos.blogspot.com/2010/02/entrevista-fogwill-por-la-reedicion-de. html>. 14 ago. 2012.

Perlongher, Néstor. Prosa Plebeya. Ensayos 1980-1992. Buenos Aires: Ediciones Colihue, 1997.

Sontag, Susan. El SIDA y sus metáforas. Barcelona: Muchnik Editores, 1988.

Weeks, Jeffrey. Elmalestar de la sexualidad: significados, mitos y sexualidades modernas. Alberto Magnet, trad. Madrid: Talasa, 1993.

Žižek, Slavoj. Visión de Paralaje. Buenos Aires: Fondo de Cultura Económica, 2006.

Revista Iberoamericana, Vol. LXXXI, Núm. 250, Enero-Marzo 2015, 233-251 
